\title{
Optimization of Cutting Frequency Electromagnetic Interuptor
}

\author{
Moez Hadj Kacem \\ University of Sfax
}

Laboratory of Electronic and Information

Technology (LETI-Sfax), E.N.I.S Tunisia

\author{
Souhir Tounsi \\ University of Sfax \\ Laboratory of Electronic and Information \\ Technology (LETI-Sfax), E.N.I.S Tunisia
}

\author{
Rfik Neji \\ University of Sfax \\ Laboratory of Electronic and Information \\ Technology (LETI-Sfax), E.N.I.S Tunisia
}

\begin{abstract}
In this paper, we describe an analytical methodology for designing an electromagnetic switch chain power an electric vehicle, reducing the cost and power consumption. The structure of the converter is modular, it has the advantage of increasing the switching frequency by stacking module either in series or in parallel. The results validate the design approach and demonstrate the advantage of the parallel structure.
\end{abstract}

\section{KEYWORDS}

electric vehicle; structure serial; structure parallel; switching frequency

\section{INTRODUCTION}

In light of high oil crises and air pollution in recent decades, the electrification of vehicles becomes a topical project. However, the production of electric vehicles (EVs) in large quantities is still hindered by their limited autonomy and their relatively high cost [1].

Naturally, the EV traction motors are driven at variable speed through an inverter voltage IGBTs leads to several problems which include that of the floating potential of the tail current, lath-up static dynamics and losses [2]. These problems lead to complications of the control circuit and the obligation under most cases the integration of a cooling system for the inverter. This is why we chose structure UPS electromagnetic switches (ES) to limit these problems. In this Directive an analytical model for sizing this type of switch is developed in parallel with a validation study and complementarity in the finite element method.

\section{STRUCTURE OF THE CHAIN DRIVE}

\subsection{Power Range}

Channel power our EVs "Fig. 1 ", consists of a permanent magnet synchronous axial flow (MSAPFA), batteries, a static

converter to electromagnetic switches (IEs) and a mechanical transmission system.

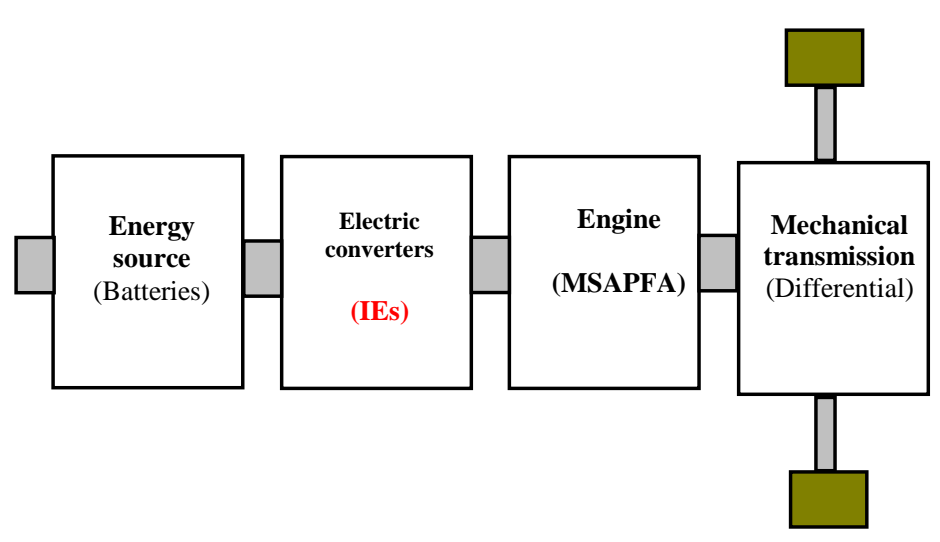

Fig.1. Traction of VE

\subsection{Channel energy conversion}

Our energy conversion chain is broken down into elements described in "Fig. 2 ". It includes, if one starts from the mains $\mathrm{AC}$, battery charger, battery electrochemistry, which is a source of electrical power board, all electronic converter, motor, charging the group (three phase rectifier, boost chopper) command and finally the mechanical transmission whose role is to adapt the characteristic mechanical load to the engine $[3,4]$.

The inverter used in our structure is a high-power converter using electromagnetic switches instead of IGBTs. These electromagnetic switches in the power range into play for our application, offer a better compromise between the voltage drop, speed and good quality control signals. 


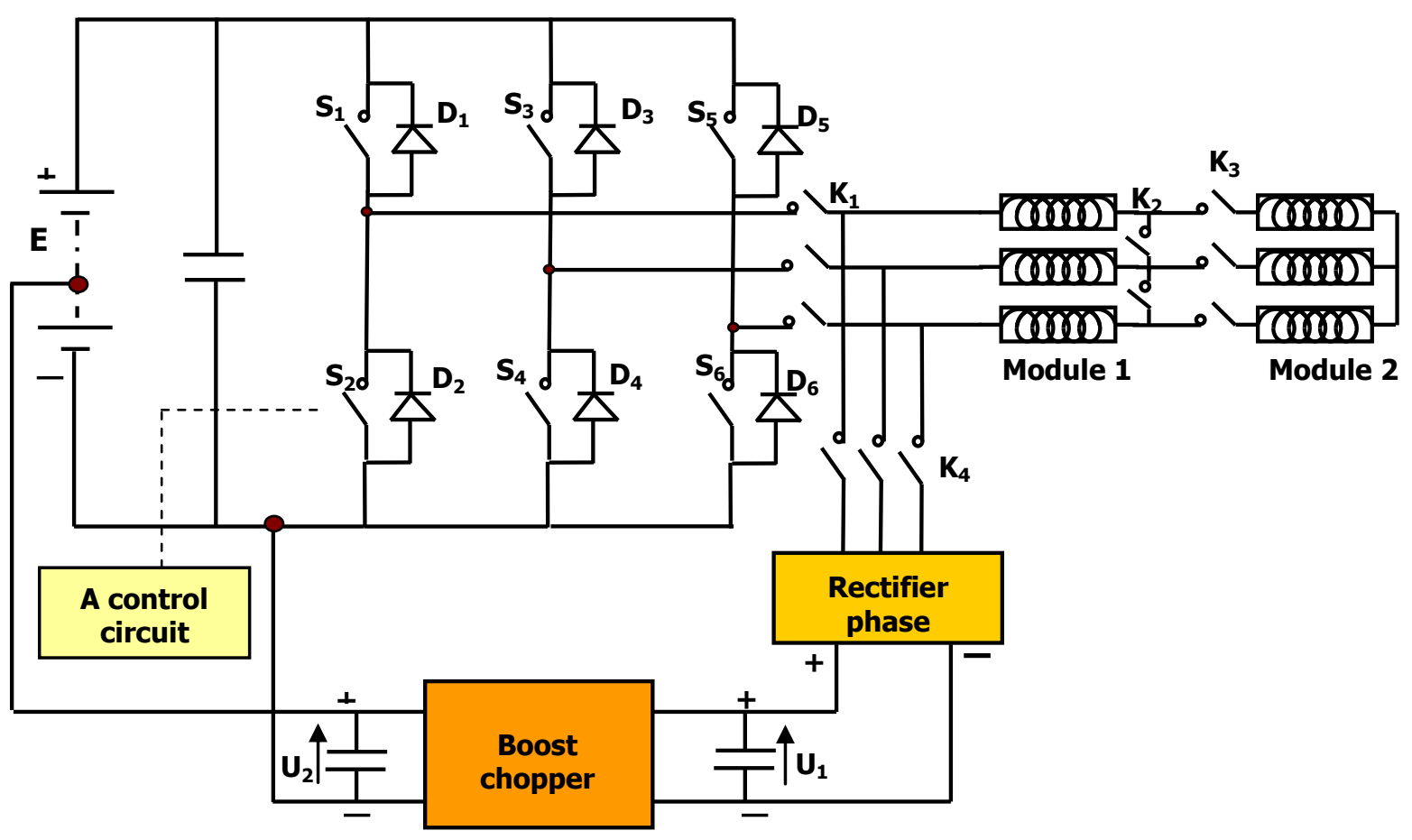

Fig.2. Diagram of the chain of energy conversion

\subsection{Energy recovery system}

During the phases of acceleration and constant speed operation, the motor is driven by the converter according to electromagnetic switches a control strategy trapezoidal profile of the phase current of the motor in phase with the electromotive force, leading to a minimization of the energy consumption. In this case the switches $\mathrm{K} 1$ and $\mathrm{K} 2$ are closed and $\mathrm{K} 3$ and $\mathrm{K} 4$ are opened by the action of their generating coils control. By cons, during phases of deceleration on a recoverable energy, K1 opens and closes $\mathrm{K} 3$ causing the operation of the energy recovery. In this case the motor operates as a generator. Indeed, the electromotive forces induced by three inertial force of the vehicle is transformed into a high DC voltage by a chopper boosting duty ratio optimized in order to maximize the energy recovered by the energy store in the board electric vehicle. This voltage is applied to the battery at the node reload. This node is selected in a way to maximize the energy recovered [5].

The torque required to move the electric vehicle is important because of the force of inertia. To address this problem, we thought to increase the stator flux (overfluxing), in this case the switches $\mathrm{K} 1$ and $\mathrm{K} 3$ are closed and $\mathrm{K} 2$ and $\mathrm{K} 4$ are open.

\section{ANALYTICAL DESIGN OF STATIC CONVERTER}

The converter is an inverter ES. This structure is less expensive compared to IGBT and offers good quality waveforms of voltages and currents motor power, which leads to good dynamic characteristic of electric vehicles.

\subsection{Modeling ES}

Parameters for modeling the electromagnetic switch are illustrated in figure 3. [3]

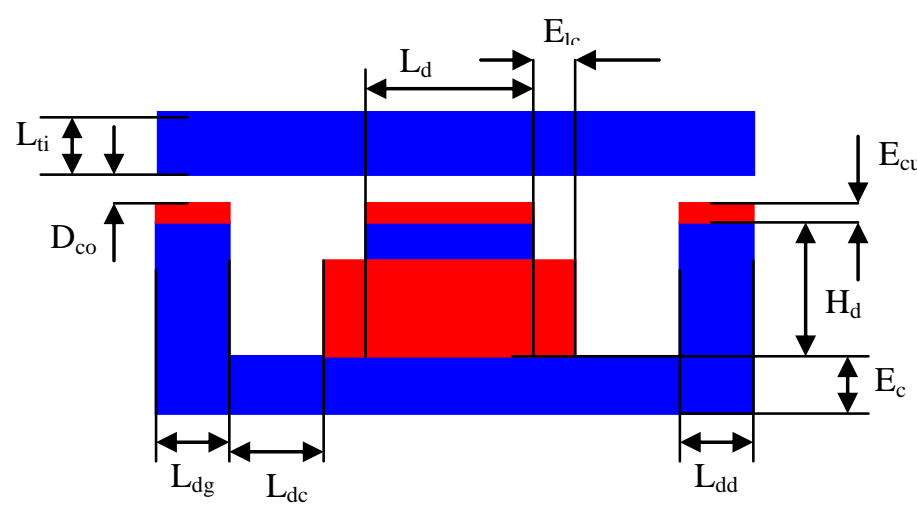

Fig.3. The geometric parameters of the ES

\section{- $\quad$ Width of the stem}

The width of the stem is obtained from the application of the theorem of conservation of the flow between the tooth which is located the coil and the rod:

$\mathrm{L}_{\mathrm{ti}}=\frac{\mathrm{B}_{\mathrm{ec}} \times \mathrm{L}_{\mathrm{d}}}{2 \times \mathrm{B}_{\mathrm{c}}}$

Where $L_{d}$ is the width of the tooth and $\mathrm{Bc}$ is the maximum induction in the rod.

Thickness of head

The thickness of the cylinder head is expressed by the following relationship: 
$\mathrm{E}_{\mathrm{cs}}=\frac{\mathrm{B}_{\mathrm{ec}} \times \mathrm{L}_{\mathrm{d}}}{2 \times \mathrm{B}_{\mathrm{cs}}}$

Where Bcs is the induction into the breach.

Width straight tooth

$\mathrm{L}_{\mathrm{dd}}=\frac{\mathrm{B}_{\mathrm{ec}} \times \mathrm{L}_{\mathrm{d}}}{2 \times \mathrm{B}_{\mathrm{d}}}$

Where $\mathrm{Bd}$ is the induction teeth left and right.

- Width of tooth left

$\mathrm{L}_{\mathrm{dg}}=\frac{\mathrm{B}_{\mathrm{ec}} \times \mathrm{L}_{\mathrm{d}}}{2 \times \mathrm{B}_{\mathrm{d}}}$

- The thickness of the coil

$\mathrm{E}_{\mathrm{lc}}=\mathrm{N}_{\mathrm{c}} \times \mathrm{D}_{\mathrm{f}}$

(5)

\subsection{Modularity of ES}

The structure of the converter is modular, it has the advantage of increasing the switching frequency by stacking module either in series or in parallel.

\section{- $\quad$ series structure}

The static converter electromagnetic switches "Fig.4" is composed of two mechanical contacts $\mathrm{S} 1$ and $\mathrm{S} 2$. Initially, the first contact is closed and the other open to avoid the problem of short circuit $[6,7]$

The structure of the series converter is shown in the following figure:

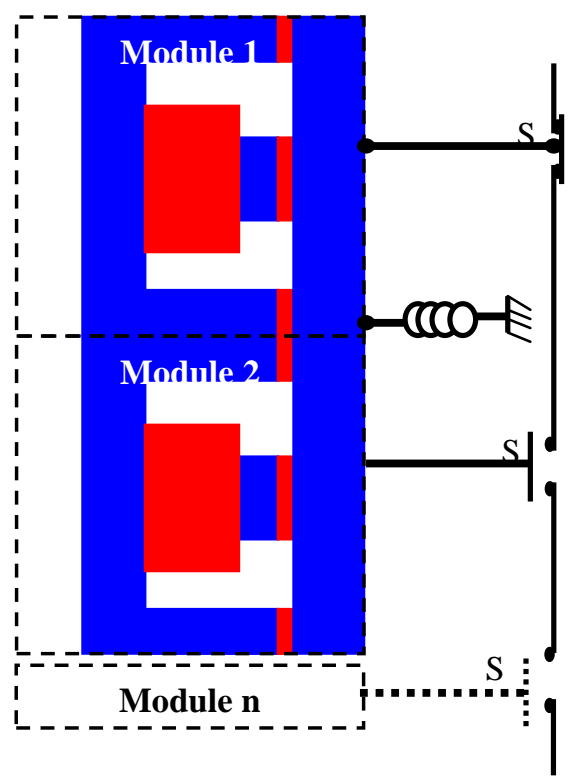

Fig.4.Series structure

This structure is composed by $\mathrm{n}$ modules in series resulting in a contact closure by energizing the coil and causing the contact opening by excitation of the coil-and by the action of a return spring [8]. The force of attraction of the rod is the sum of the forces of attraction generated by the $\mathrm{n}$ windings.
The equation of motion of the rod to the closing is subtracted from the basic relationship of the dynamics [6]:

$$
\begin{aligned}
\mathrm{nms} \times \mathrm{M}_{\mathrm{t}} \times \frac{\mathrm{dv}}{\mathrm{dt}} & =\mathrm{nms} \times \frac{\mu_{0} \times \mu_{\mathrm{r}}}{4} \times \frac{\mathrm{I}^{2} \times \mathrm{N}_{\mathrm{sb}}^{2}}{\left(\mathrm{E}_{\mathrm{cu}}+\mathrm{D}_{\mathrm{co}}-\mathrm{x}_{\mathrm{t}}\right)^{2}}-\mathrm{k} \times \mathrm{x}_{\mathrm{t}} \\
\text { Avec } \quad \mathrm{v} & =\frac{\mathrm{dx}_{\mathrm{t}}}{\mathrm{dt}}
\end{aligned}
$$

Where Mt is the weight of the rod, nms is the number of modules in series, $\mathrm{v}$ is the velocity of the rod, $\mathrm{k}$ is the constant of the spring rate and $\mathrm{xt}$ is the displacement of the rod.

The equation of motion of the rod to the opening is given by the following relationship:

$M_{t} \times \frac{d v}{d t}=2 \times k\left(D_{c o}-x_{t}\right)$

- $\quad$ parallel structure

The parallel structure "Fig.5" has the advantage of a frequency of opening and closing of the switches of the converter significantly higher compared to the series structure, since these actions occur by action of the force of attraction $n$ the generating coils.

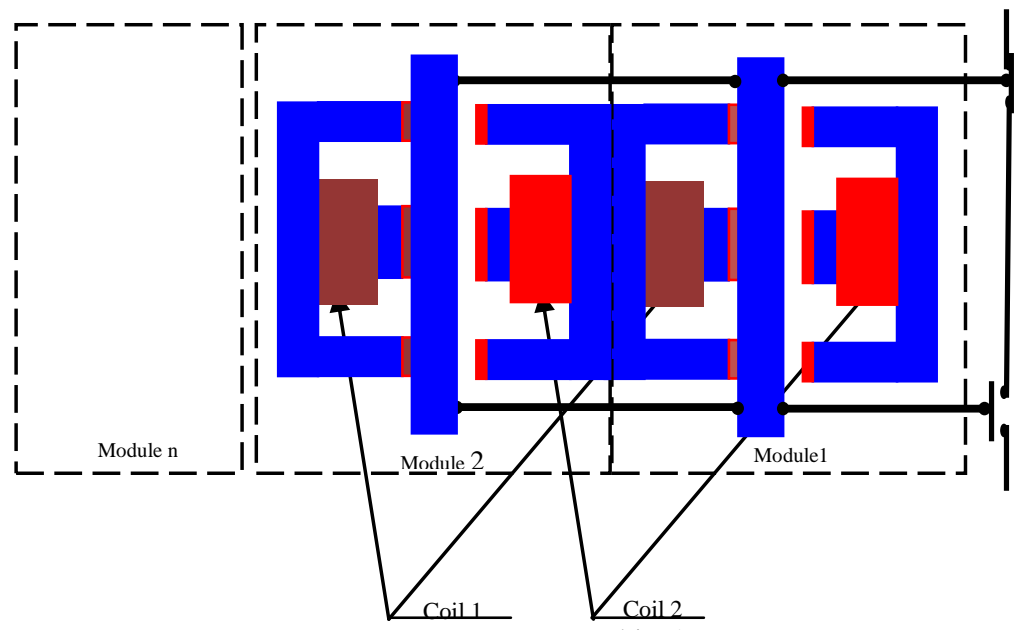

Fig.5. Parallel structure

The equation of motion of the rod to the closing and opening is derived from the basic relationship of the dynamics [40]:

$$
\mathrm{nmp} \times \mathrm{M}_{\mathrm{t}} \times \frac{\mathrm{dv}}{\mathrm{dt}}=\mathrm{nmp} \times \frac{\mu_{0} \times \mu_{\mathrm{r}}}{4} \times \frac{\mathrm{I}^{2} \times \mathrm{N}_{\mathrm{sb}}^{2}}{\left(\mathrm{E}_{\mathrm{cu}}+\mathrm{D}_{\mathrm{co}}-\mathrm{x}_{\mathrm{t}}\right)^{2}}
$$

\section{VALIDATION APPROACH TO DESIGN}

\subsection{Series structure}

\subsubsection{Closing time of the movable core:}

Solving equation (8) for a number of modules nms varying from 1 to 5 shows the development of the closing time of the movable core in accordance with movement of the stem (Fig. 6.). 


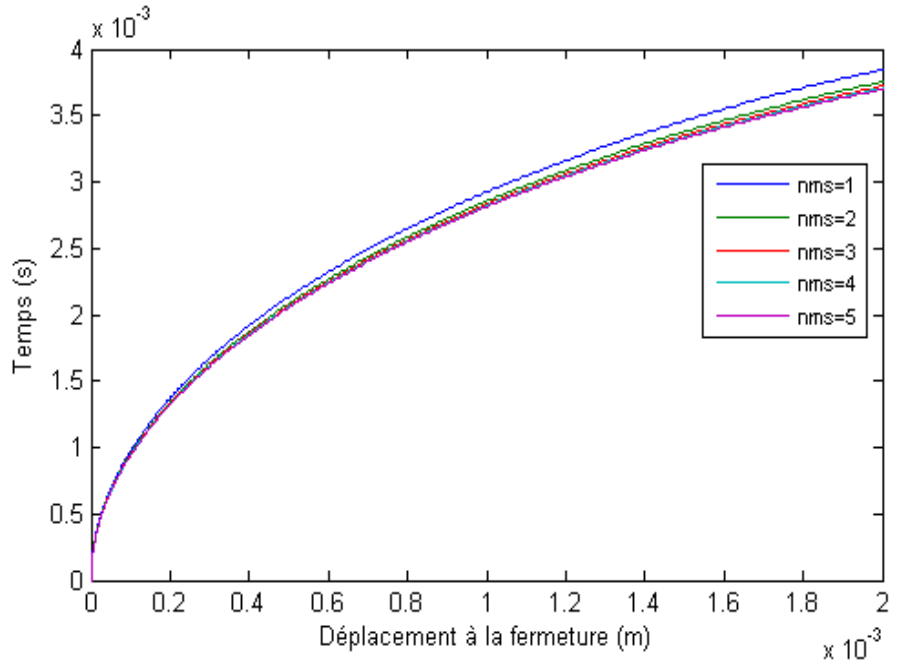

Fig.6. Evolution of the closing time of the movable core in accordance with movement of the rod

The closure time decreases slightly increasing the number of modules. For this reason, one module is sufficient for the stacked structure series.

The total closure of the switch corresponding to a displacement of the rod is made of $2 \mathrm{~mm}$ for a period

$$
\text { Ton }=0.0036 \mathrm{~s} \text {. }
$$

\subsubsection{Opening time the plunger:}

Figure 7 illustrates the evolution of the open time of the movable core as a function of displacement of the rod for a number of modules nms varying from 1 to 5 .

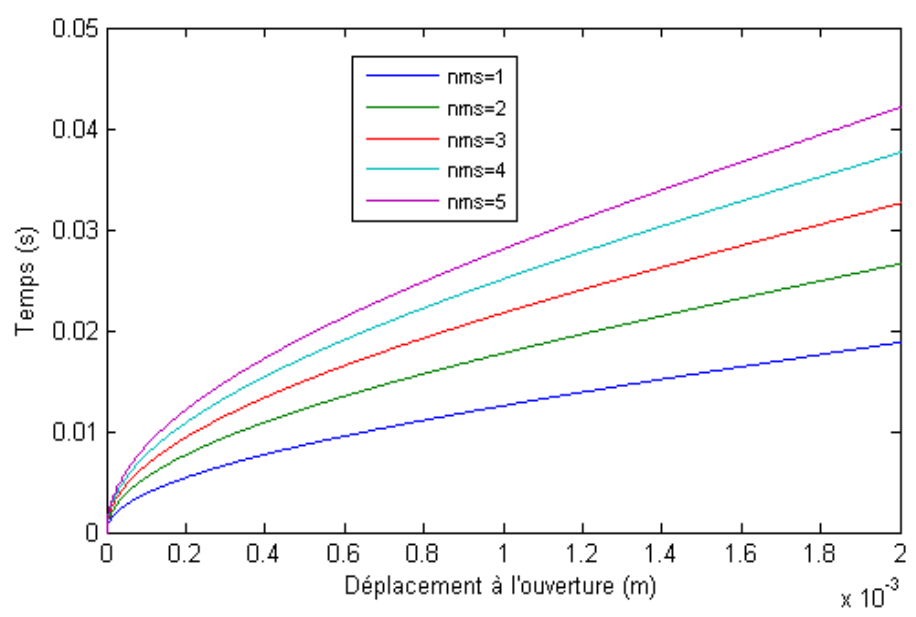

Fig.7. Evolution time of opening and closing of the movable core in accordance with movement of the rod

Open time decreases greatly reducing the number of modules, since the mass of the rod increases, this again proves the advantage of a single module for this stack structure.

The total closure of the switches corresponding to a movement of the rod $2 \mathrm{~mm}$ resulting in a term Toff $=0.018 \mathrm{~s}$.

This time is relatively small compared to the closing time which leads to one of the asymmetrical control the opening and closing of the power contact also with a decrease in the frequency of opening and closing.
Deduced therefore the switching frequency of the rod:

$$
\begin{gathered}
f=\frac{1}{\text { Ton }+ \text { Toff }} \\
f=18,52 \mathrm{~Hz}
\end{gathered}
$$

\subsection{Parallel structure}

Solving the equation of the parallel structure (9) for a number of modules nms varying from 1 to 5 shows changes in time of closing and opening of the movable core in accordance with movement of the rod (Fig. .8.).

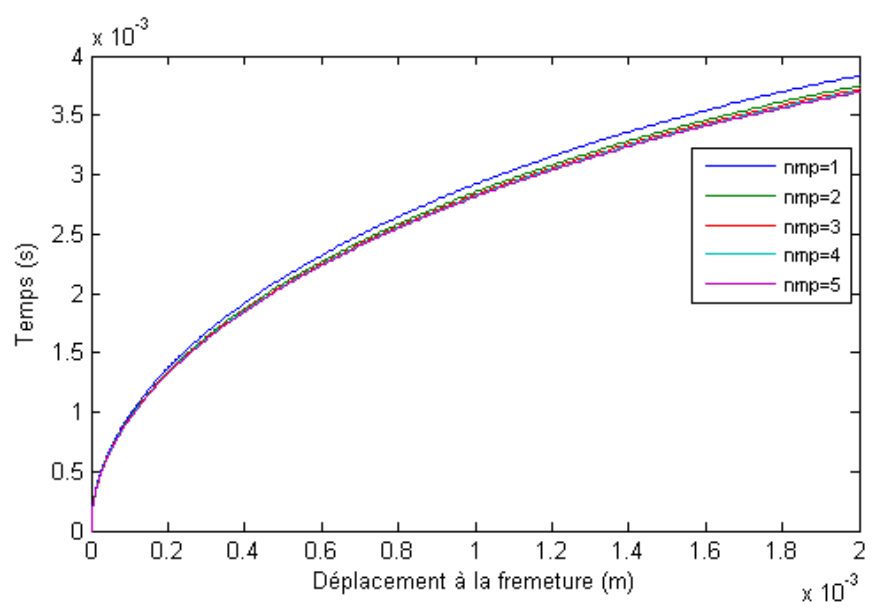

Fig.8. Evolution of the closing time of the movable core in accordance with movement of the rod

This parallel structure the opening time and closing the lowest, since the closing and opening of the power contacts are carried by the action of two generator coils. The increase module nms slightly increases the time of closing and opening of contacts, which led us to choose one module to push the problem of rising cost structure.

The closing and opening of switches corresponding to the total displacement of the rod $2 \mathrm{~mm}$ resulting in a time

Toff $=$ Ton $=0.0036 \mathrm{~s}$.

Deduced therefore the switching frequency of the rod: $f=138,9 \mathrm{~Hz}$

This structure is the switching frequency the higher, the more it has the advantage of the absence of springs which increases its service life and reduces maintenance costs.

\section{CONCLUSION}

Channel power ES is chosen to solve the problem of electric traction since it is less dissipative and less expensive compared to in IGBTs

The results show that our design method is validated. The parallel structure presents the switching frequency higher compared to the series structure, moreover it offers the advantage of the absence of springs which increases its lifespan and reduces the manufacturing cost.

\section{REFERENCES}

[1] B.MULTON, L. HIRSINGER : «Problème de la Motorisation d'un Véhicule Electrique »; Revue 3E.I n ${ }^{\circ}$ mars 96 pp.55-64.J. Clerk Maxwell, A Treatise on Electricity and Magnetism, 3rd ed., vol. 2. Oxford: Clarendon, 1892, pp.68-73. 
[2] A. AMMOUS, B. ALLARD, H. MOREL: «Transient temperature mesurements and modeling of IGBT's under short circuit», IEEE transaction electronic devices, vol. 13, $\mathrm{n}^{\circ} 1,1998$, p. $12-25$.

[3] M.HADJ KACEM, S.TOUNSI et R. NEJI: « Control of an Actuator DC Energy-saving dedicated to the Electric Traction »; International Journal of Computer Applications (0975 - 8887) Volume 54- No.10, September 2012.

[4] S. TOUNSI, M. HADJ KACEM et R. NEJI: « Design of Static Converter for Electric Traction »; International Review on Modelling and Similations (IREMOS) Volume 3, N. 6, December 2010, pp. 1189-1195.

[5] M.HADJ KACEM, S.TOUNSI et R. NEJI: «Systemic Design and Control of Electric Vehicles Power Chain »; IJSTR, volume1, $\mathrm{n}^{\circ} 2012$.
[6] V. SMET: «Fiabilité et analyse de défaillances de modules de puissance à IGBT »; JCGE'08 LYON, 16 et 17 décembre 2008.

[7] S. TOUNSI, R. NEJI, F. SELLAMI: «Contribution à la conception d'un Actionneur à Aimants Permanents pour Véhicules Electriques en vue d'Optimiser l'Autonomie»; Revue Internationale de Génie Electrique, volume 9/6, 2006, pp. 693-718. Edition Lavoisier.

[8] N. JANIAUD : «Modelisation Du Systeme De Puissance Du Vehicule Electrique En Regime Transitoire En Vue De L'optimisation De L'autonomie, Des Performances Et Des Couts Associes»; Thèse de Doctorat 2011, E.PARIS SUD. 